\title{
Forecasting Unusual Trend of COVID-19 Progression in Pakistan
}

\author{
Sadaf A.M ${ }^{1^{*}}$ and Adnan J. ${ }^{2}$
}

1. Department of Biology, Govt College Rehmatabad, Rawalpindi, Higher Education Department Punjab.aqasaliaqas@gmail.com

2. Department of Mathematics, Quaid e Azam University, Islamabad. Ajaveed@math.qau.edu.pk

\author{
Corresponding Author \\ Malik Sadaf Ali \\ Lecturer in Biology \\ Govt. College Rehmatabad, Rawalpinidi \\ Higher Education Department, Punjab, Pakistan \\ Tel: $+92-3335686750$ \\ Email: aqasaliaqas@gmail.com
}

\begin{abstract}
The observed data of COVID-19 progression in Pakistan for first 50 days from the first patient been reported has shown quite an unusual trend which is in opposition to clear exponential spread pattern of any infectious disease. The data of positive cases of 50 days of disease progression has been collected from COVID-19 dashboard of Pakistan and analyzed to see the graphical trend and to forecast the behaviour of disease progression for next 30 days. Mathematical equations regarding exponential growth are used to analyse the disease progression and different possible trajectories are plotted to understand the approximate trend pattern. The possible projections estimated 20k-456k positive cases within 80 days of disease spread in Pakistan. Although, the disease progression pattern is not perfectly exponential, it is still threatening a major fraction of susceptible population and demands effective strategic planning and control.
\end{abstract}

Key Words: COVID-19; Pakistan; exponential growth; projection 


\section{Introduction}

The corona virus disease was first reported as cluster of cases of pneumonia like respiratory illness in Wuhan, China in December 2019 [1]. The virus belongs to family Coronaviridae which consists of ssRNA, enveloped viruses having clubbed shaped spikes projecting out of their surface [2][3]. According to the WHO report published on 12 January 2020, the pathogen responsible for respiratory illness in China was isolated and characterized in China on January 07, 2020. The causative pathogen was named as novel Corona Virus (2019n-CoV) by WHO and later named as SARS-CoV-2 by International committee on Taxonomy of Viruses So other possible pathogens including influenze, adenovirus andSevere Acute Respiratory Syndrome (SARC-CoV) were ruled out for the reported novel infection in China[4]. COVID-19 showed exponential growth after its appearance in China as the number of infected cases globally reached to 109577 by 09 March 2020 when WHO declared it pandemic [5].

Pakistan reported its first two cases of COVID-19 on 27 February 2020 when two persons with travelling history from Iran were found positive in diagnosis [6]. Pakistan's geographical location made its natives on high risk being neighbour of China and Iran which had become epicentre of corona virus illness. Although, the epidemic was announced in China and Iran a month ago, with its outspread in other global regions as well, Pakistan did not take strategic steps in time and international travelling influx was kept in practice till end of February 2020. Later, within 15 days after the reporting of first infected case, the number of positive cases reached up to 20 on 12 March [7]. Pakistan realized the threat of epidemicalarmingly by local transmission on 13 March 2020, when first local transmission case was reported from Sindh who was a 52 years old patient with no international travelling history [8].

Pakistan started taking drastic decisions from reporting of fist local transmission case of COVID-19. National Security Committee(NSC) decided the implementation of social 
distancing in the country and Educational institutes were announced to be closed throughout the country as well as sealing of borders with Iran and Afghanistan on 13 March 2020 [9]. National Security committed devised National Action Plan for COVID-19 as a policy document for ensuring that all guiding principles for outbreak preparedness, containment and mitigation were followed [10]. As per directions of NSC, important preventive measures were taken to ensure minimal national morbidity and mortality. Preparedness was determined by available and required health resources, surveillance mechanism and response potential and also by scaling up of logistic mechanism. Quarantine centres were established in Taftan at PakIran border to identify and quarantine the Pakistani nationals returning from Iran which has been showing exponential growth of the disease. Screening facilities were established at airports also along with the mechanism of tracing contacts of infected cases. Up to April 18, 2020, there are 163 quarantine centres in Pakistan has been established with a bed capacity of 23557 and 25 diagnostics centres [11][12].The testing capacity was less than 500/day during early March 2020 which has been uplifted to 6500/day [13].

In Pakistan, the disease progression data is monitored and published by National Institute of Health (NIH) through live dashboard [14]. Only 21 cases were reported on 12 March 2020 when Pakistan declared the policy of Lock down to decrease the risk of infection spread. The coming days were quite threatening as the patient number was constantly increasing in all regions of Pakistan. On 20 March 2020, the number of positive cases has crossed the figure of 500 and just within next two days the number of cases reached 1000 on 22 March 2020. At this stage the disease progression was showing a sharp rise on daily basis and Pakistan Government showed the threat of having about 50,000 patients till 25 April, 2020 in a report submitted to Supreme Court of Pakistan on 5 April 2020 [15]. On 11 April 2020, the confirmed positive cases were reported to be 5038. The highest daily increase among the first 
fifty days of disease progression was observed on 6 April, 15 April, 16 April and 17 April 2020 with daily new cases $577,543,488$ and 465 respectively [14].

The forecasting of disease spread over a given time is quite significant for the Government and the National Health System of a country in order to combat the upcoming worst situation. Although the actual trend can always be different from data based model because of impact of ground realties and unseen social, economical and cultural factors, the data based models and predictions are proved quite helpful to decide new strategies or even to transform the existing practices. We have analyzed the available data of positive cases in Pakistan, to understand the existing trend of disease spread in order to forecast the upcoming trend lines.

This article is organized in the following order. The ongoing section 1 is of introduction which includes some introductory remarks about the infectious disease as well as about its growth in Pakistan. Moreover, it highlights the measures adopted by the government of Pakistan to combat this pandemic. Section 2, deals with the methodology that has been adopted to predict the progression in near future. The growth of the viral infections is approximated by relying on mathematical equations of exponential growth. In section 3,results and discussion are summarized in order to sum up the manuscript. The whole article is concluded in section 4

\section{Methodology}

The methodology of this study was based on desktop analytical study approach. The data of positive cases was collected from electronic media resources especially from COVID19 dashboard of National Institute of Health (NIH) Pakistan. The analysis was principally based upon exponential growth of corona virus and hence functional analysis was performed upon unchecked growth of COVID-19. Although there were infinite dimensions of possibilities of exponential function, the model was expressed in terms of simple exponential function $2^{x}$. Comparative analysis was performed on theoretical explanation of exponential growth and observed data of positive cases in Pakistan from emergence of infection till 50th day of disease 
progression. In consequence, possible trajectories were drawn by using exponential function and the best approximated trajectory was considered to forecast the upcoming scenario of viral disease in the country.

\subsection{Prognostication of Covid-19 based on Mathematical Equations}

The pandemic covid-19 is affecting almost all population around the globe. WHO assumes it is growing in an affected region exponentially if proper precautionary measures are not adopted by that community. For the sake of simplicity, if it is assumed that an infectious person transmit virus to two people and this goes on. After one month total projected number of infected people would be $10.4 \times 10^{8}$.

Mathematically, if $x$ represent number of days and $y$ gives the number of people got infected with the pattern explained above, than we have

$$
y=2^{x}
$$

This simplest transmission pattern can even be proved worst than any explosion (Fig 1).

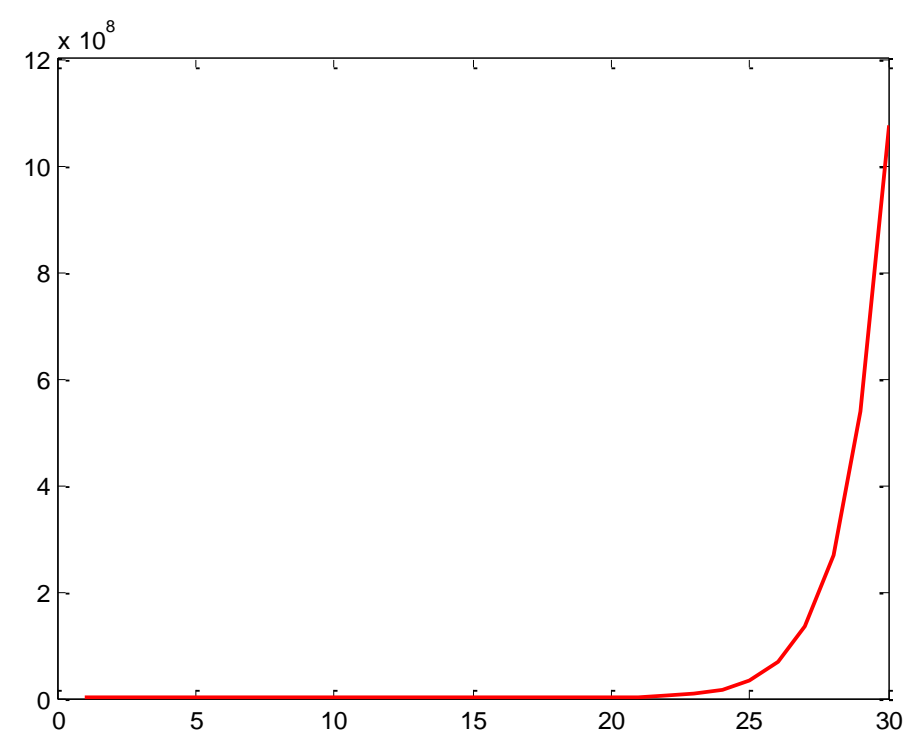

Fig.1: Graph of transmission to at least two people daily 


\subsection{Growth pattern of observed positive Covid-19 in Pakistan}

The data of positive cases of COVID-19 in Pakistan is collected from NIH live dashboard and plotted in Graph in order to understand the observed exponential function. The first patient when reported in February initiated the possible exponential growth. After fifty days the confirmed cases of covid-19 in Pakistan were around seven thousand. From February to April, fifty days were schemed along $\mathrm{x}$-axis and the numbers of confirmed cases of patients each day were depicted by the y-axis. The actual trend observed in MATLAB is given in the following.

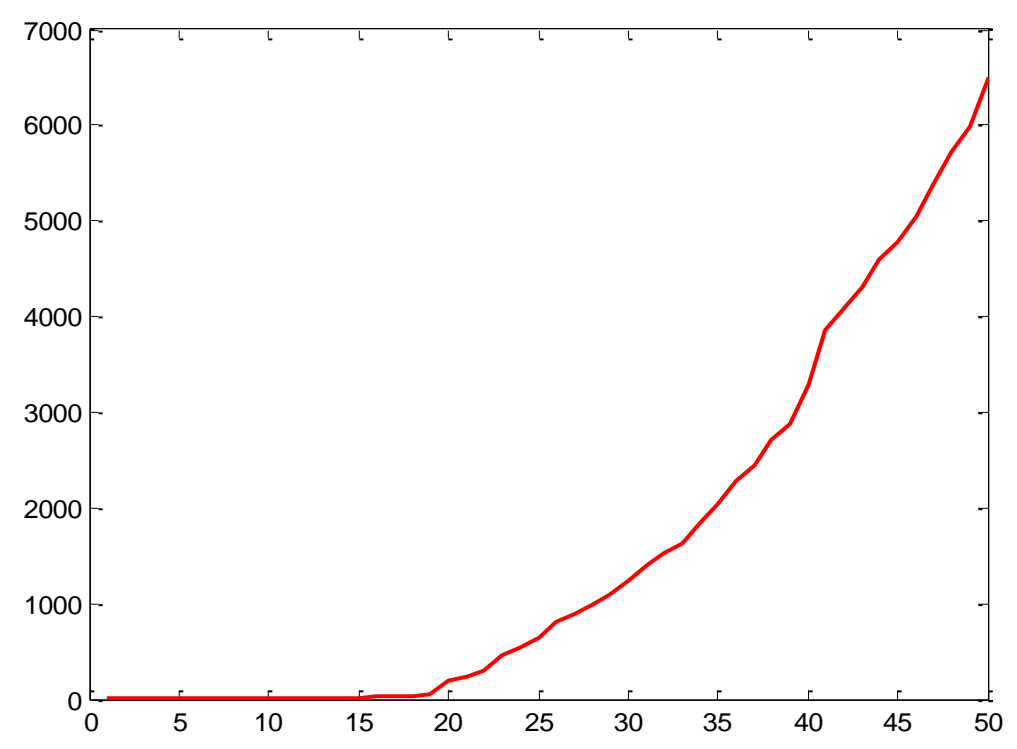

Fig. 2: Confirmed (Observed) cases of covid-19 in first fifty days in Pakistan

\subsection{Mathematical Equations for Possible exponential function}

The search for the selection of possible exponential function for Pakistan started afterwards. This was based on the graphical behaviour of data available on dashboard of covid-19 on the site of national institute of health $(\mathrm{NIH})$ Islamabad. Experts from WHO warned about the transmission of virus from a single person is expected to affect four people per day. The available data of Pakistan neither follow this rule, nor to the one explained in section 2.2.The graphical demonstration of the observed data is exhibiting mixed trend of linear and 
exponential progression rate. The nearest approximate in terms of a function in the time frame of first fifty days is coined as follow.

$$
y=e^{x / n}
$$

Where $\mathrm{n}$ can be an interval from 1 to 9.Different trajectories were plotted for this function to match with the actual data. Four such trajectories were selected for comparison (Fig3). Numbers of patients were plotted on y-axis and $\mathrm{x}$-axis displayed number of days after diagnosing first case in Pakistan.

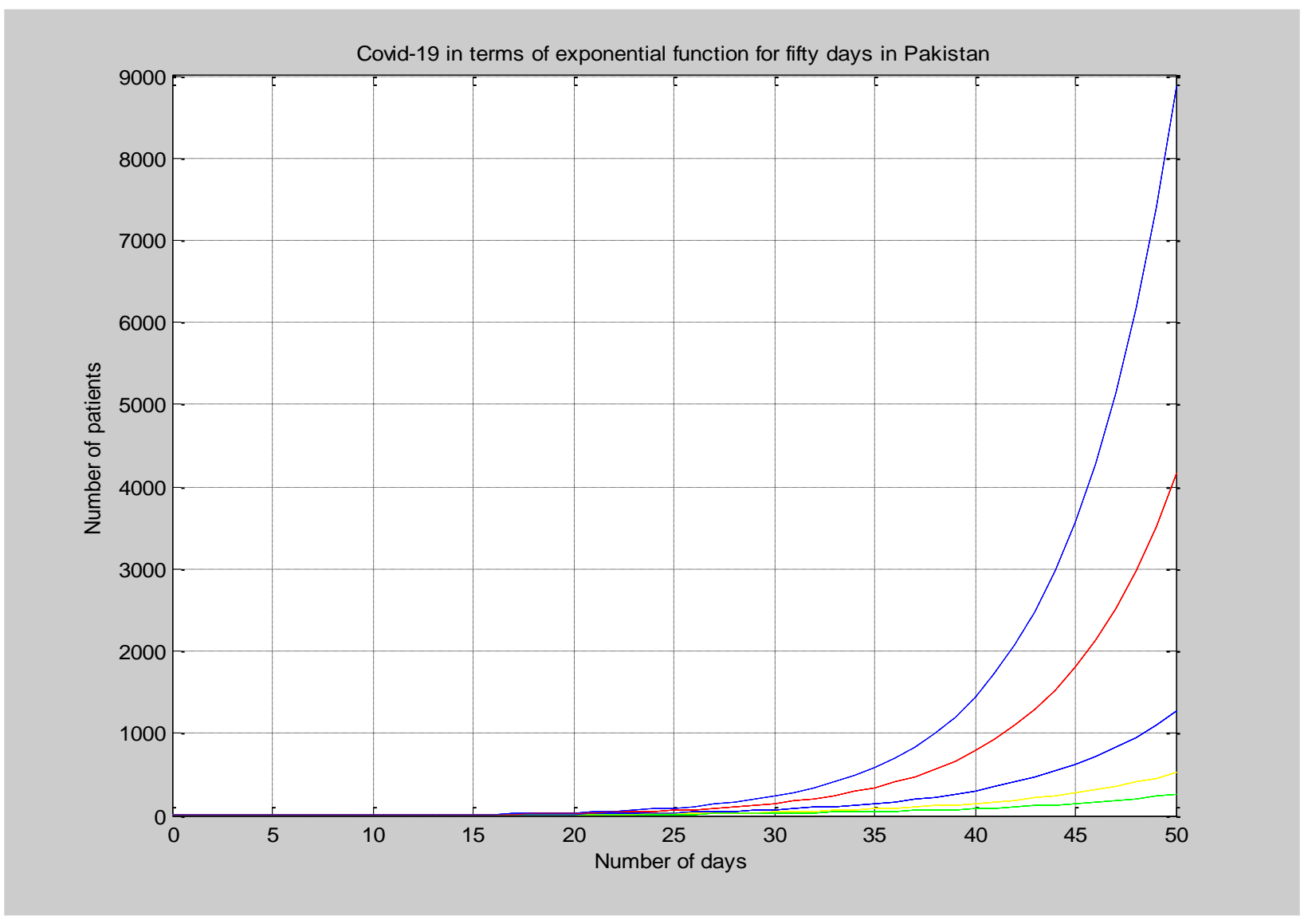

Fig. 3: Different trajectories of the curve given in Eq. 1.

\section{Results and Discussion}

The data of COVID-19 positive cases reported by NIH, Pakistan was analyzed for first fifty days of disease progression from 26 February 2020 to 15 April 2020. On 26 February 2020 only two cases were reported in Karachi, Pakistan and the number of positive cases 
increased up to 28 on 13 March 2020 when lock down was started in the country. The disease progression was quite slow initially but after 13 March 2020, the next few days rung the bell when a sharp rise started to appear in the curve and exponential growth was shown which ultimately approached 6505 positive cases on 15 April 2020, the $50^{\text {th }}$ day of disease progression. The graph plotted for observed data showed overall gradual. Approximate exponential rise with certain exceptional days when comparatively low daily patient increase was reported (Fig 1).

The graphical pattern of observed disease progression in Pakistan was compared with possible trajectories and it was found that graphical pattern of covid-19 in Pakistan matches with the curve presented by dash lines in blue colour. Mathematically, it is the graph of the equation.

$$
y=e^{\frac{x}{5.5}}
$$

Considering this trend after 60 days i.e. at the start of May, 2020, the projected number of infectious people in Pakistan would be 54671.

The disease spectrum provided in a report from Chinese centre for disease control and prevention [16] indicated that $81 \%$ of COVID-19 cases are mild in nature with negligible or no symptoms whereas $14 \%$ of cases show severe symptoms that require proper treatment for recovery. Among total cases, only 5\% cases develop to critical stage that require intensive care and lead to morbidity count. However, the disease spectrum observed in Pakistan is found somewhat unusual as compared to Chinese spectrum as positive cases reported so far found quite below than the forecasted number by Pakistan which would be 50,000 at the end of April. We calculated projected number of confirmed, hospitalized cases which would be 54671 on 27April 2020 as per possible exponential growth curve whereas the number of observed positive cases as per trend line of observed data would by 12000 which accounts almost $22 \%$ of the projected 54671. The difference between projected and observed numbers of positive 
cases can possibly be due to effectiveness of preventive measures by authorities,lower number of screening tests, effect of climate conditions, and complementary immune support of some previous extensive vaccination program or unavailability of data of those patients which recovered themselves due to better immunity or less severity of infection. This can also be dedicated to the strain diversity of corona virus in Pakistan which has been reported different from corona virus strain of China [17].

\subsection{Projections of Covid-19 in Pakistan for 80 days of disease progression}

In order to obtain a close projected number of confirmed positive cases for next 30 days, we generalized the possibility that almost $16-22 \%$ of projected number could be found as positive cases.On the basis of above decided criteria, the projected and observed number of cases were calculated by using the equation (1).

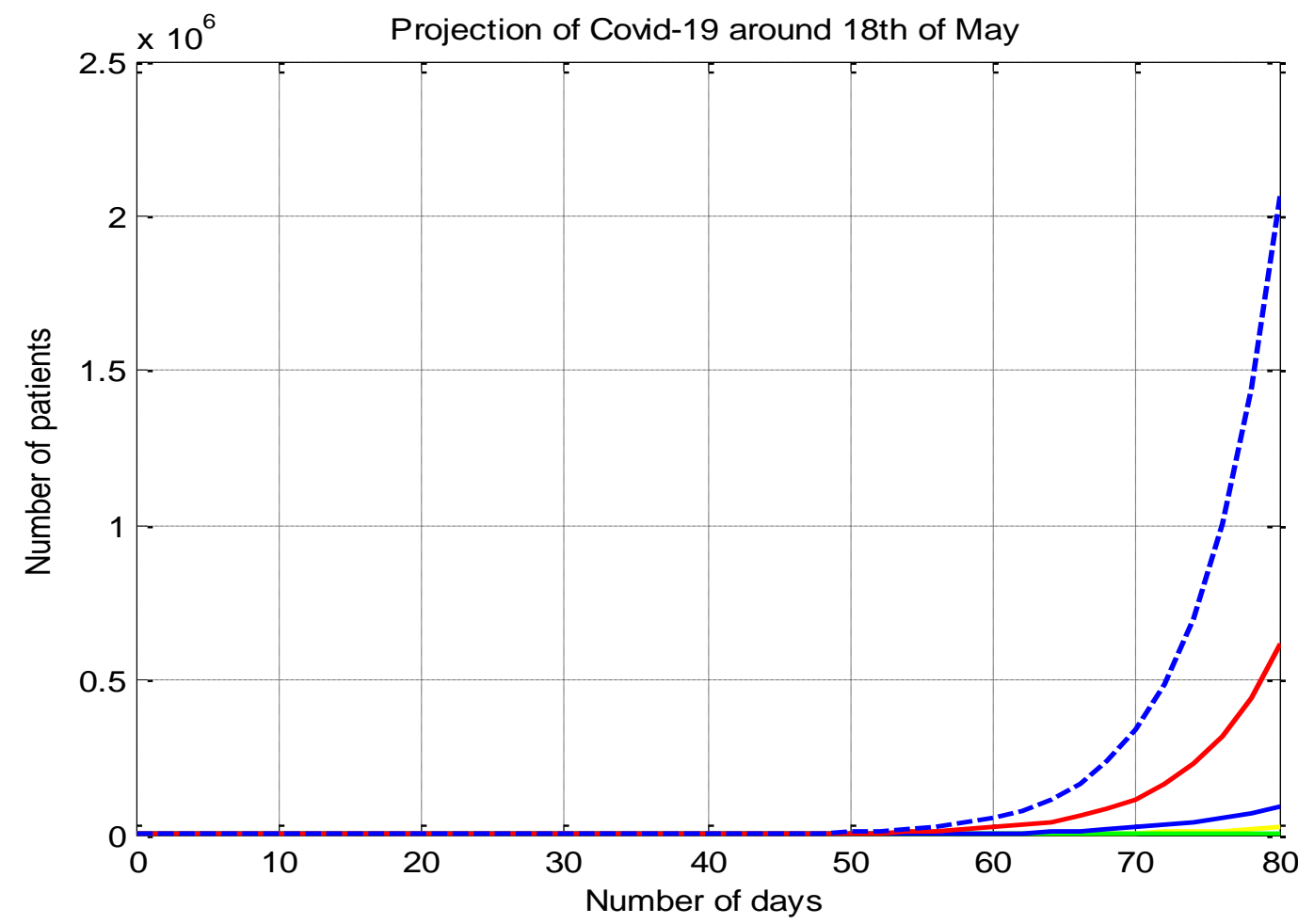

In a worst case scenario, if the pattern goes on to exponential growth after fifty days, then projected number of patients would be as of given by case-1.

Case-1 $\left(y=e^{\frac{x}{5.5}}\right)$ Blue dashed curve 


$$
\begin{gathered}
\text { Proj Patients }=2.075 \times 10^{6} \\
\text { Proj Patients }=2075000 \\
\text { Observed Patients }(22 \% \text { of Proj Patients })=456500
\end{gathered}
$$

In a mild severe case scenario, like the trend observed in UK, USA and Italy, then the expected number of infected population would be closer to case- 2 projection.

Case-2 $\left(y=e^{\frac{x}{6}}\right)$ Red curve

$$
\begin{gathered}
\text { Proj Patients }=6.157 \times 10^{5} \\
\text { Proj Patients }=615700 \\
\text { Observed Patients }(22 \% \text { of Proj Patients }=135454
\end{gathered}
$$

Finally, if the constraints applied by the state to combat the exponential viral spread moves towards the winning side to flatten the curve, then we have the possibility as follow

\section{Case-3 $\left(y=e^{\frac{x}{7}}\right)$ Bluesolid curve}

$$
\begin{gathered}
\text { Proj Patients }=9.2 \times 10^{4} \\
\text { Proj Patients }=92000 \\
\text { Observed Patients }(22 \% \text { of Proj Patients }=20240
\end{gathered}
$$

There are many factors that are affecting the growth of viral infection in Pakistan. Theoretical studies suggest its progression to be of exponential nature but practically, it appeared some time linear also. Keeping all this in mind and sticking to the theoretical approach as well, we drew possible three trend lines based on the initial data to forecast its numbers in near future.

\section{Conclusion}

The trend of COVID 19 in Pakistan is extremely unusual since it is a well known fact that such kind of viral diseases transfer exponentially. Initially, the observed data of Pakistan starts its path following the exponential growth in first 20 days. Then it moves on linearly which is very astonishing from biological perspective. Linearity pattern is also unusual. After that again it showed some exponential growth. It is indeed difficult to model such kind of behaviour 
exhibiting dual trend. The projection in terms of linear equation undermines the transfer behaviour of this viral disease. Neither it is linear in theoretical description of disease nor was it linear in countries like China, Iran Italy UK and USA. The neared approximation in terms of exponential growth is therefore coined. Considering properly the confirmed positive cases of COVID-19 and mixed trend shown by the curve till to date, three possible curves were presented using exponential function of $\mathrm{e}^{\mathrm{x} / 5.5}, \mathrm{e}^{\mathrm{x} / 6}$, and $\mathrm{e}^{\mathrm{x} / 7}$. These are responsible in projecting the range [20k 465k] of positive cases of COVID-19 for coming days. These calculations provide the forecast that Pakistan may have positive cases in a range of 20240456500 depending upon the unusual pattern of disease progression curve in 80 days of disease progression. If curve flattening cannot be achieved up to end of May 2020, the number of positive case will reach to a number that will not be manageable as per the current capacity of National Health System of Pakistan therefore, strict implementation of preventive and screening must be made through the country.

\section{Ethics Approval and Consent to participate}

Not Applicable

\section{Conflict of Interest}

The authors show no conflict of interest

\section{Funding}

This research did not receive any specific grant from funding agencies in the public, commercial, or not-for-profit sectors.

\section{Author's contribution}

Sadaf A.M devised the study, collected the data and wrote the first draft of the paper. Adnan J. analyzed the data mathematically and processed the mathematical projections of the data. Sadaf A and Adnan J.wrote the discussion. Both authors reviewed the script and endorsed the submission. 


\section{References}

1. Guan WJ, Ni ZY, Hu Y, Liang WH, Ou CQ, He JX, Liu L, Shan H, Lei CL, Hui DSC, Du B, Li LJ, Zeng G, Yuen KY, Chen RC, Tang CL, Wang T, Chen PY, Xiang J, Li SY, Wang JL, Liang ZJ, Peng YX, Wei L, Liu Y, Hu YH, Peng P, Wang JM, Liu JY, Chen Z, Li G, Zheng ZJ, Qiu SQ, Luo J, Ye CJ, Zhu SY, Zhong NS (2020) Clinical Characteristics of Coronavirus Disease 2019 in China. $N$ Engl J Med. https://doi.org/10.1056/NEJMoa2002032

2. de Groot RJ, Baker SC, Baric R, Enjuanes L, Gorbalenya AE, Holmes KV, Perlman S, Poon L, Rottier PJ, Talbot PJ, Woo PC, Ziebuhr J (2011). "Family Coronaviridae". In King AM, Lefkowitz E, Adams MJ, Carstens EB, International Committee on Taxonomy of Viruses, International Union of Microbiological Societies. Virology Division (eds.). Ninth Report of the International Committee on Taxonomy of Viruses. Oxford: Elsevier. pp. 806-28. ISBN 978-0-12-384684-6.

3. Almeida JD, Berry DM, Cunningham CH, Hamre D, Hofstad MS, Mallucci L, McIntosh K, Tyrrell DA (November 1968). "Virology: Coronaviruses". Nature. 220 (5168): 650.

4. https://www.who.int/csr/don/12-january-2020-novel-coronavirus-china/en/. Accessed 12January 2020.

5. https://www.who.int/emergencies/diseases/novel-coronavirus-2019/situation-reports. (Report 49, Dated 09 March 2020)

6. Ali I. Pakistan confirms first two cases of coronavirus, govt says "no need to panic". https://www.dawn.com/news/amp/1536792. Accessed 27 Feb 2020.

7. COVID-19 live dashboard (Pakistan): National Institute of Health Islamabad. https://www.nih.org.pk/covid-2019-live-dashboardf/. Accessed 12 Mar 2020

8. Raza, S.; Rasheed, M.A.; Rashid, M.K. Transmission Potential and Severity of COVID-19 in Pakistan. Preprints 2020, 2020040004 (doi: 10.20944/preprints202004.0004.v1).

9. Web Desk. Pakistani schools, madrassas, universities to remain shut till April 5 amid corona virus scare. https://www.thenews.com.pk/latest/628643. Accessed 13 March 2020-04-18

10. National Action Plan of for COVID-19 (Pakistan) https://www.nih.org.pk/wp-content/uploads/2020/03/COVID-19 NAP V2 13 March 2020

11. List of Province-wise COVID-19 Quarantine Facilities Pakistan. http://covid.gov.pk/facilities/QuarantineFacililties. Accessed 17 April 2020

12. List of Labs for screening COVID-19. http://covid.gov.pk/facilities/Labs-new.pdf

13. Media briefing of Prime Minister Pakistan on 18 April 2020. https://www.youtube.com/watch?v=dowfPwg4ZVY

14. COVID-19 dashboard, Government of Pakistan. http://covid.gov.pk/stats/pakistan

15. Sohail K. Corona might affect 50-000 in Pakistan by April 25. https://www.thenews.com.pk/print/639764 Accessed on April 5, 2020

16. Wu Z, McGoogan JM (2020) Characteristics of and Important Lessons From the Coronavirus Disease 2019 (COVID-19) Outbreak in China: Summary of a Report of 
72314 Cases From the Chinese Center for Disease Control and Prevention. JAMA. https://doi.org/10.1001/jama.2020.2648

17. Chinese strain of corona virus different than Pakistani one (Dr Atta Interview to Geo TV). https://www.geo.tv/latest/279904. Accessed on 30 March 2020. 